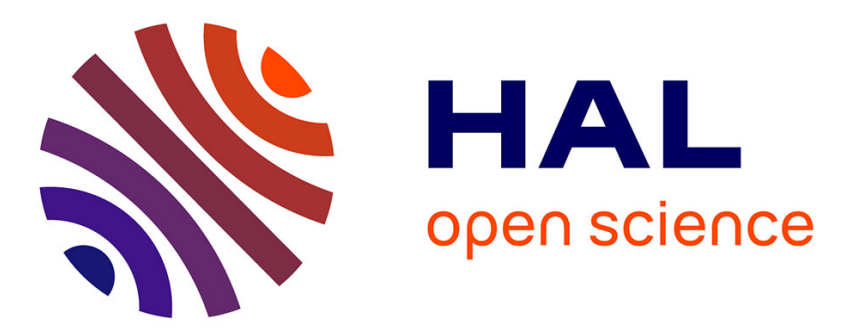

\title{
Thermal degradation of polyesters filled with magnesium dihydroxide and magnesium oxide
}

Amandine Viretto, Rodolphe Sonnier, Aurélie Taguet, Belkacem Otazaghine, Laurent Ferry, José-Marie Lopez-Cuesta, Christian Lagreve

\section{To cite this version:}

Amandine Viretto, Rodolphe Sonnier, Aurélie Taguet, Belkacem Otazaghine, Laurent Ferry, et al.. Thermal degradation of polyesters filled with magnesium dihydroxide and magnesium oxide. Fire and Materials, 2016, 40 (3), pp.445-463. 10.1002/fam.2299 . hal-02906425

\section{HAL Id: hal-02906425 \\ https://hal.science/hal-02906425}

Submitted on 7 Jan 2021

HAL is a multi-disciplinary open access archive for the deposit and dissemination of scientific research documents, whether they are published or not. The documents may come from teaching and research institutions in France or abroad, or from public or private research centers.
L'archive ouverte pluridisciplinaire HAL, est destinée au dépôt et à la diffusion de documents scientifiques de niveau recherche, publiés ou non, émanant des établissements d'enseignement et de recherche français ou étrangers, des laboratoires publics ou privés. 


\title{
Thermal degradation of polyesters filled with magnesium dihydroxide and magnesium oxide
}

\author{
Amandine Viretto ${ }^{1,2}$, Rodolphe Sonnier ${ }^{1, *}{ }^{\dagger}$, Aurélie Taguet ${ }^{1}$, Belkacem Otazaghine ${ }^{1}$, \\ Laurent Ferry ${ }^{1}$, Jose-Marie Lopez-Cuesta ${ }^{1}$ and Christian Lagrève ${ }^{2}$ \\ ${ }^{1}$ Centre des Matériaux de l'Ecole des Mines d'Alès, 6 Avenue de Clavières, 30319, Alès Cedex, France \\ ${ }^{2}$ ACOME, 52 rue du Montparnasse, 75014, Paris, France
}

\begin{abstract}
SUMMARY
Magnesium dihydroxide (MDH) was evaluated as char promoter into different polymers exhibiting various chemical structures. Char promotion was characterized using thermogravimetric analysis and pyrolysiscombustion flow calorimetry. Gases released during pyrolysis were identified using pyrolysis coupled gas chromatography/mass spectrometry and thermogravimetric analysis coupled Fourier transform infrared spectroscopy. Relationships between the MDH effect (according to the char content and its thermal stability) and the chemical structure of the host polymers were identified. It was shown that MDH can be a good char promoter for aromatic polyesters such as polybutylene terephtalate and polyethylene terephtalate. Char promotion can be considered as one of the main mode-of-action of MDH at low or moderate filler content. An optimum was observed at approximately 20wt.\% of MDH. Magnesium oxide was also studied as substitute to $\mathrm{MDH}$ to avoid hydrolysis phenomena due to the water release. But it was demonstrated that MDH was more efficient as a char promoter for polybutylene terephtalate than magnesium oxide.
\end{abstract}

KEY WORDS: flame retardancy; polyesters; poly(butylene terephthalate); magnesium dihydroxide;

magnesium oxide

\section{INTRODUCTION}

The wide use of polymer materials in everyday life is led by their outstanding combination of properties, low weight, low cost, and ease of processing. However, polymers are also known for their high flammability usually accompanied by the release of corrosive or toxic gases and smoke during combustion. Accordingly, improving the flame retardancy of polymers is a key issue for extending their use to most applications $[1,2]$.

The scientific literature has presented various strategies for improving polymer flame retardancy, which depend mainly on the nature of the polymer $[3,4]$. The main route to reduce the flammability of polymers is the incorporation of fillers and additives, which can act according to different modesof-action in condensed or gas phases [2]. Until recently, many flame retardants were halogen based. These compounds act mainly in gas phase by scavenging the high energy radicals $\left(\mathrm{H}^{\circ}\right.$ and $\left.\mathrm{OH}^{\circ}\right)$ responsible for flame propagation. This flame inhibition effect leads to incomplete combustion with intense smokes and toxic products [5]. Moreover, some halogenated flame retardants are considered toxic [6] and persistent, with a significant long term environmental impact [7]. The alternatives to halogenated flame retardants include metal hydroxides, hydrocarbonates, borates, phosphorous compounds, nitrogen compounds, silicon compounds, and nanoparticles [2].

*Correspondence to: Rodolphe Sonnier, C2MA, Ecole des Mines, 6 Avenue de Clavières, Alès Cedex, France.

†E-mail: Rodolphe.Sonnier@mines-ales.fr 
In this paper, we will mainly focus on the hydrated mineral fillers and especially on magnesium dihydroxide (MDH). Metal hydroxides provide effective flame retardancy when they are used in polymers. Aluminim trihydroxide (ATH) and MDH are the most widely used [8]. MDH is a wellknown flame retardant and smoke suppressor in thermoplastic polymers (polyolefin [9] and polyamide $[10,11])$ and in thermoplastic elastomers $[12,13]$. High loading levels of 50-60wt.\% are generally required to achieve good fire performances in polymers [8]. MDH decomposes through an endothermic reaction to give magnesium oxide $(\mathrm{MgO})$ with water release. The decomposition starts at about $300-330^{\circ} \mathrm{C}$ giving off about $31 \%$ of its mass as water. The associated endothermic energy of this reaction is about $1450 \mathrm{~J} / \mathrm{g}$ [9]. $\mathrm{MDH}$ acts as a fire retardant through five main mechanisms [13]: (1) the dilution of the organic phase by replacement of the polymer matrix; (2) its endothermic decomposition, which slows down the thermal decomposition of the polymer; (3) the release of water, which dilutes the fuels in vapor phase; (4) the absorption of energy due to the heat capacity of $\mathrm{MDH}$ and $\mathrm{MgO}$, which reduces the thermal energy available to degrade the polymer (the heat capacity of the filler is generally lower than that of the polymer; nevertheless, the residue from filler decomposition remains in the condensed phase and absorbs heat, whereas the polymer is completely or almost completely volatilized during pyrolysis); and (5) the mineral residue, which accumulates at the surface and insulates the substrate from the heat source. If $\mathrm{MDH}$ or $\mathrm{MgO}$ promotes also charring, the organomineral residue should be much more efficient as barrier layer. It is the objective of this article to study the char promotion of both fillers in relation to the structure of the host polymer.

Various polyesters with different chemical structures were selected. The polybutylene terephtalate (PBT), an aromatic polyester, was especially investigated. PBT is a saturated thermoplastic polyester produced by polycondensation reaction of terephtalic acid and 1,4-butanediol [14]. This polymer has remarkable properties such as high rate of crystallization, good solvent resistance, thermal stability, and excellent processability [15]. PBT is quite flammable, and it is necessary to improve its flame retardancy.

The thermal stability and flammability of thermoplastic polyesters, mainly filled with MDH, are investigated in this study. Many polymers, such as polyamides and polyesters, are sensitive to hydrolysis, which leads to an earlier degradation of material properties. This explains the great interest addressed to the hydrolytic degradation mechanisms and kinetics of these polymers $[16,17]$. The degradation of PBT properties is due to hydrolysis of ester groups in the backbone leading to chain scissions [18]. This hydrolysis phenomenon could be promoted by the water release from hydroxides. Using metal oxides instead of hydroxides may limit the hydrolytic degradation of PBT while acting as a flame retardant. Recent literature reports an interest in the use of oxide particles [19-22] as synergistic agents in addition to the usual fire retardant additives. Metal oxide particles showed an ability to change the pathway of polymer decomposition and promote the formation of a protective barrier during the thermal degradation. This barrier reduces the mass transfer from the sample to the flame and the heat transfer from the flame to the condensed phase [19]. In this work, $\mathrm{MgO}$ in the micronic range was used in replacement of $\mathrm{MDH}$ to avoid hydrolysis of PBT, and its effect on the fire behavior was studied.

In the first part of this article, the influence of the presence of MDH on the thermal degradation of 12 polymers was investigated. This study allowed selecting PBT as good charring polymer in the presence of MDH. The second part attempted to optimize the char promotion effect in PBT through two ways. In the first approach, MDH content was varied to identify a threshold value above which charring is not further promoted. The second approach dealt with the replacement of $\mathrm{MDH}$ by $\mathrm{MgO}$ to avoid early degradation of PBT by hydrolysis.

\section{EXPERIMENTAL PART}

\subsection{Materials}

The polymers used in this study were various aromatic and aliphatic polyesters, polymers with pendant ester groups and polycarbonate (PC). According to their structure, these polymers were divided into four series A, B, C, and D (Table I). Series A gathers thermoplastic aliphatic polyesters (polylactique acid 


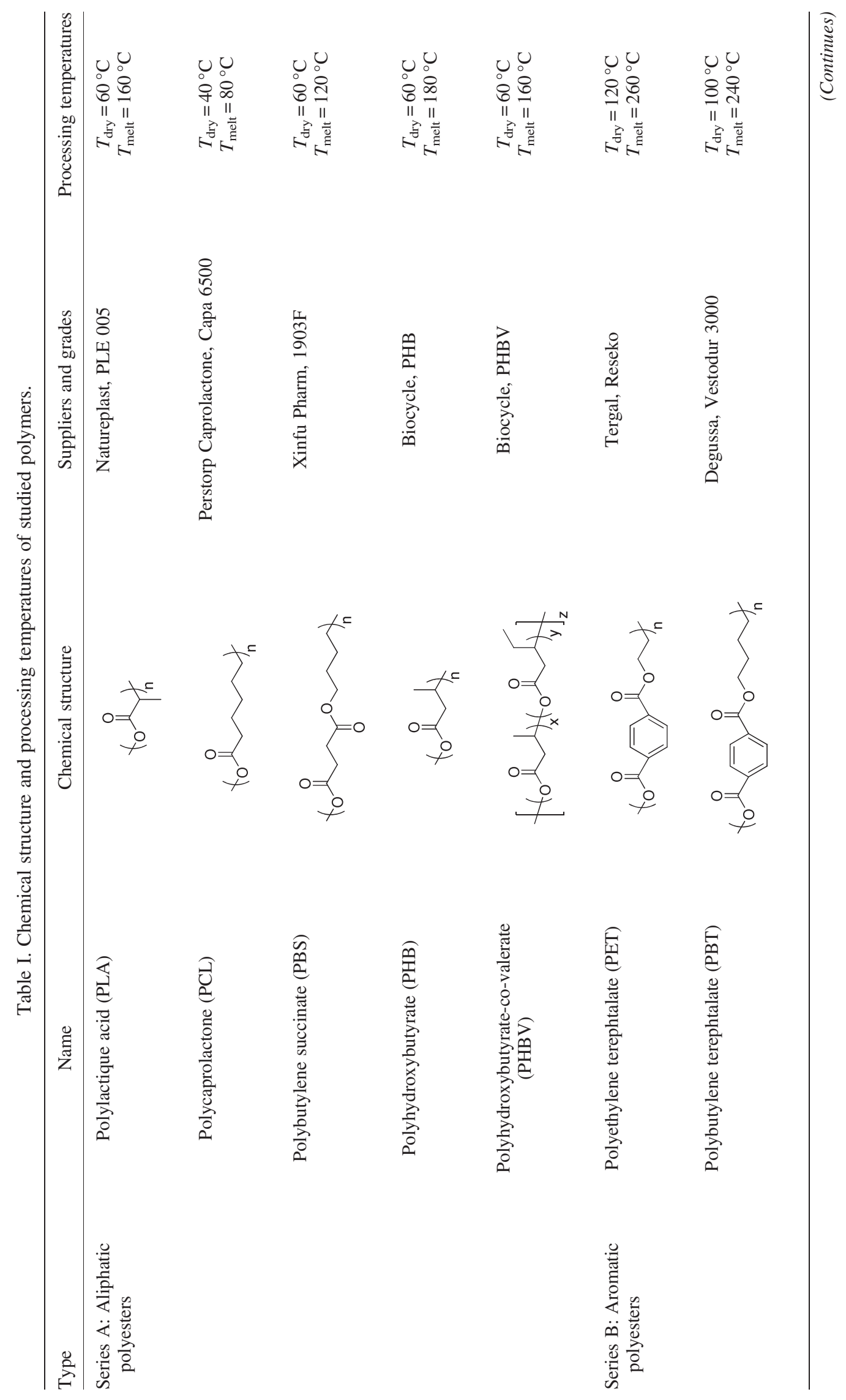




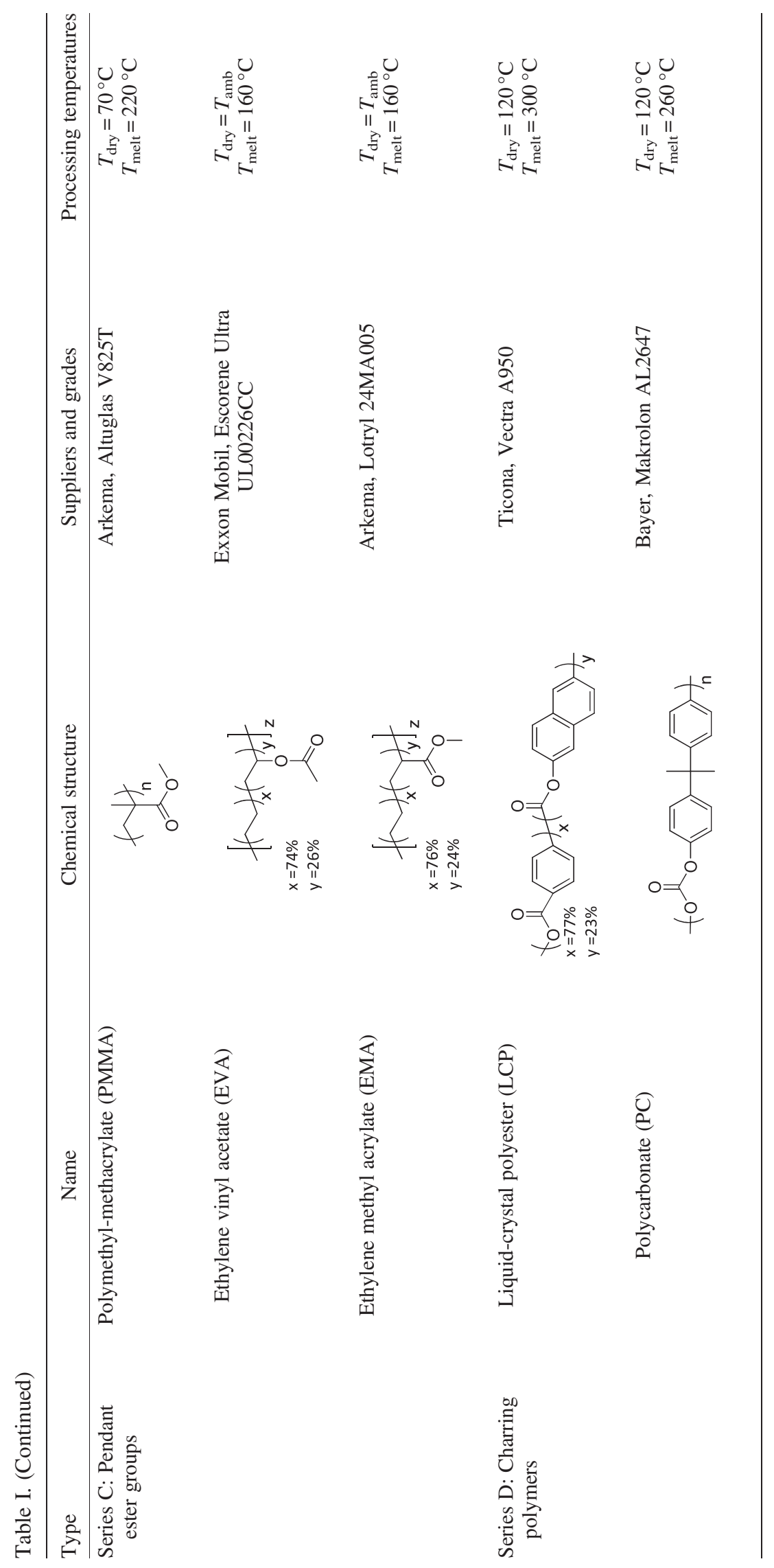


(PLA), polycaprolactone, polybutylene succinate, polyhydroxybutyrate (PHB) and PHB-co-valerate (PHBV)), whereas series B corresponds to thermoplastic aromatic polyesters (polyethylene terephtalate (PET) and PBT). Series C includes thermoplastic polymers or copolymers with pendant ester groups (ethylene vinyl acetate, ethylene methyl acrylate (EMA), and polymethyl-methacrylate). Whereas the polymers from series A, B, and C hardly form char during pyrolysis, series D gathers polymers able to char easily, which present an ester group such as liquid crystal polyester (LCP) or a carbonate group such as PC.

The characteristics of $\mathrm{MDH}$ and $\mathrm{MgO}$ used in this study are shown in Table II.

\subsection{Processing}

The polymers filled with $\mathrm{MDH}$ or $\mathrm{MgO}$ were obtained using a micro-compounder (DSM Xplore, $15 \mathrm{~cm}^{3}$ ). The blends were prepared under the following conditions: $60 \mathrm{rpm}, 10 \mathrm{~min}$, and processing temperatures $T_{\text {melt }}$ described in Table I. It should be noticed that the decomposition temperature range of MDH is above the processing temperature of all the studied polymers, except LCP. In the case of this last formulation, MDH probably starts to degrade during processing.

Polybutylene terephtalate was also compounded with 10 or $25 \mathrm{wt}$. $\%$ of MDH using a co-rotating twinscrew extruder Clextral BC21 and injection-molded using a 50-t Krauss-Maffei equipment (Munich, Germany) to prepare specimens for cone calorimeter tests. It is believed that compounding of PBTMDH is quite difficult because of the hydrolytic degradation of PBT in the presence of MDH. We have not observed any problem to prepare these blends, maybe because of the moderate content of MDH.

\subsection{Characterizations}

Thermogravimetric analyses (TGAs) were carried out using a PerkinElmer Pyris-1 TGA thermo balance for samples of $10 \pm 2 \mathrm{mg}$. For each sample, a run was carried out at a heating rate of $10^{\circ}$ $\mathrm{C} / \mathrm{min}$ from room temperature to $900^{\circ} \mathrm{C}$ under nitrogen flow of $20 \mathrm{~mL} / \mathrm{min}$. The gases released from the pyrolysis were analyzed by Fourier transformed infrared (FTIR) spectroscopy. The gases were sent to the gas cell through a transfer line heated at $200^{\circ} \mathrm{C}$. The FTIR analyses were carried out using a Bruker IFS66 spectrometer (wavelength range of 4000-400 $\mathrm{cm}^{-1}$ and resolution of $2 \mathrm{~cm}^{-1}$ ). Moreover, the FTIR spectrometer was also used in transmission mode ( $\mathrm{KBr}$ pellets) to characterize the solid residues. The solid residues were also studied using energy-dispersive X-ray spectroscopy (environmental scanning electron microscopy was equipped with an Oxford energy dispersive X-ray spectrometry (EDX) sensor).

Flammability was investigated using a pyrolysis combustion flow calorimeter (PCFC), which was developed by Lyon et al. [23]. The sample $(2 \pm 0.5 \mathrm{mg})$ was first heated from 80 to $750{ }^{\circ} \mathrm{C}$ at $1{ }^{\circ} \mathrm{C} / \mathrm{s}$ in a pyrolyzer under nitrogen flow, and the degradation products were sent to a combustor where they mixed with oxygen in excess at $900^{\circ} \mathrm{C}$. In such conditions, these products were fully oxidized. Heat release rate (HRR) was then calculated by oxygen depletion according to Huggett's relation (1 kg of consumpted oxygen corresponds to $13.1 \mathrm{MJ}$ of released energy) [24]. Very small samples (several milligrams) could be analyzed using PCFC. At this microscale, some flame retardant effects (as barrier effect) are not effective. Nevertheless, the temperature of the different steps of degradation, the heat released during each step, and the char promotion effect are very important parameters to evaluate the flammability of a material and the PCFC allows studying all these parameters.

Table II. Physicochemical properties of studied MDH and metal oxides.

\begin{tabular}{llc}
\hline Name and stands & Suppliers and product references & Particle size $(\mu \mathrm{m})$ \\
\hline Magnesium dihydroxide, $\mathrm{Mg}(\mathrm{OH})_{2}$ & Albemarle Corp., Magnifin H10 & $d_{10}=0.4$ \\
& & $d_{50}=0.8$ \\
Magnesium oxide, $\mathrm{MgO}$ & Prolabo, 52126 & $d_{90}=1.6$ \\
& & $d_{10}=6.1$ \\
& & $d_{50}=110.2$ \\
& $d_{90}=189.5$ \\
\hline
\end{tabular}


The evolved gases during thermal degradation were also analyzed using pyrolysis-gas chromatography/mass spectrometry (Py-GC/MS) analysis. A Pyroprobe 5000 pyrolyzer (CDS Analytical, Oxford, PA, USA) was used to flash pyrolyze the samples in a helium environment. The pyrolyzer is supplied with an electrically heated platinum filament. One coil probe enables the pyrolysis of samples (less than $1 \mathrm{mg}$ ) placed in a quartz tube between two pieces of quartz wool. The same sample was heated at $900^{\circ} \mathrm{C}$. The pyroprobe 5000 is interfaced to a 450-GC gas chromatograph (Varian) by means of a chamber heated at $270^{\circ} \mathrm{C}$. In the oven, the initial temperature of $70^{\circ} \mathrm{C}$ was raised to $250^{\circ} \mathrm{C}$ at $10^{\circ} \mathrm{C} / \mathrm{min}$. The column is a Varian Vf-5ms capillary column $(30 \mathrm{~m} \times 0.25 \mathrm{~mm})$, and helium $(1 \mathrm{~mL} / \mathrm{min})$ was used as the carrier gas; a split ratio was set to 1:50. The gases were introduced from the GC transfer line to the ion trap analyzer of the 240-MS mass spectrometer (Varian) through the direct-coupled capillary column. Identification of the products was achieved comparing the observed mass spectra to those of the National Institute of Standards and Technology (NIST) mass spectral library.

Fire behavior was studied using a cone calorimeter (Fire Testing Technology), which is a powerful tool to investigate the fire behavior of polymers. A horizontal sample sheet of $100 \times 100 \times 4 \mathrm{~mm}^{3}$ was placed at $2.5 \mathrm{~cm}$ below a conic heater and isolated by rock wool. The samples were exposed to $50 \mathrm{~kW} / \mathrm{m}^{2}$ irradiance in well-ventilated conditions (air rate $24 \mathrm{~L} / \mathrm{s}$ ) and in the presence of a spark igniter to force the ignition. HRR was determined according to oxygen depletion (Huggett's relation [24]). Mass loss, $\mathrm{CO}$ and $\mathrm{CO}_{2}$ release rates, and smoke opacity were also recorded continuously. This test was performed according to the ISO 5660 standard.

\section{RESULTS AND DISCUSSION}

\subsection{Influence of $M D H$ on thermal degradation of various polyesters}

In this section, the influence of MDH on the degradation of various polyesters from the series $\mathrm{A}$ to $\mathrm{D}$ was investigated by TGA, PCFC, and Py-GC/MS.

The addition of MDH significantly changes the thermal stability of the studied polymers. Figures 1-4 show the thermogravimetric curves and the HRR curves of four polymer matrices: PLA, PBT, EMA, and LCP with and without $10 \mathrm{wt} \%$ of MDH. They are representative of the series $\mathrm{A}, \mathrm{B}, \mathrm{C}$, and $\mathrm{D}$, respectively.

Pyrolysis combustion flow calorimeter and TGAs are in good agreement for all studied (pure and filled) polymers. Contrarily to TGA, the release of non-combustible gases is not detected in PCFC. Therefore, since peaks of HRR at low temperature could be observed for PLA, PBT, and LCP filled with $\mathrm{MDH}$ (series $\mathrm{A}, \mathrm{B}$, and $\mathrm{D}$, respectively), it is confirmed that the earlier degradation (also
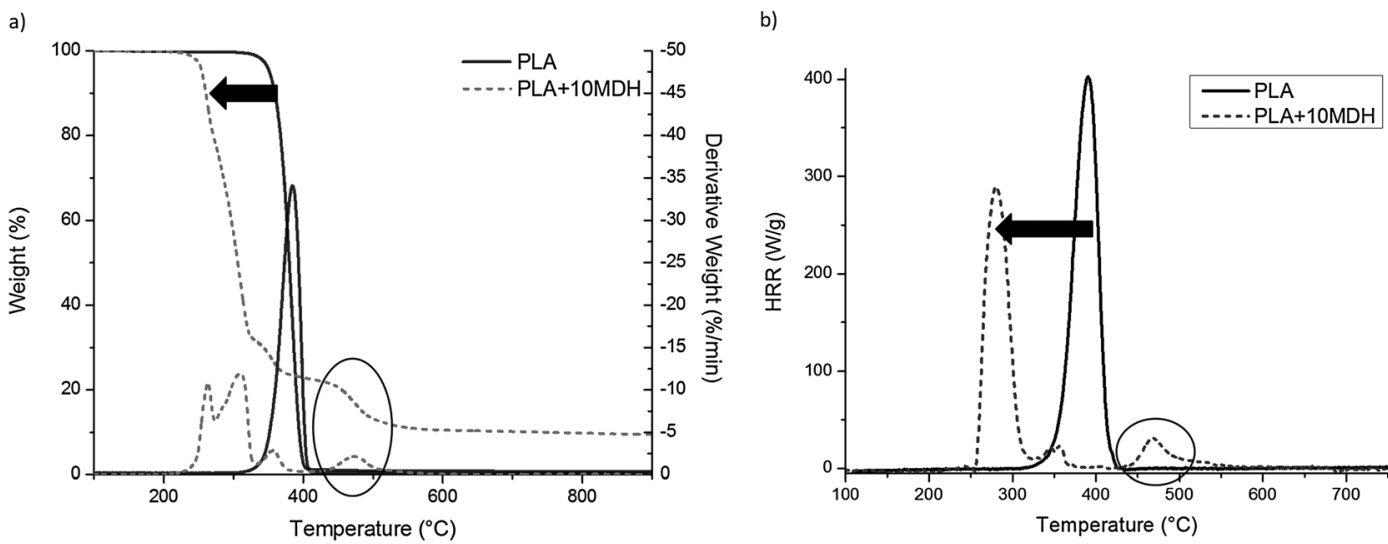

Figure 1. (a) Weight (\%) and derivative weight (\%/min) versus temperature with heating rate $\beta=10^{\circ} \mathrm{C} / \mathrm{min}$ obtained by thermogravimetric analyses under nitrogen atmosphere for PLA with and without $10 \mathrm{wt}$.\% of MDH. (b) HRR (W/g) versus temperature obtained by PCFC analyses with a heating rate of $\beta=1{ }^{\circ} \mathrm{C} / \mathrm{s}$ under nitrogen atmosphere for PLA with and without 10wt.\% of $\mathrm{MDH}$. 


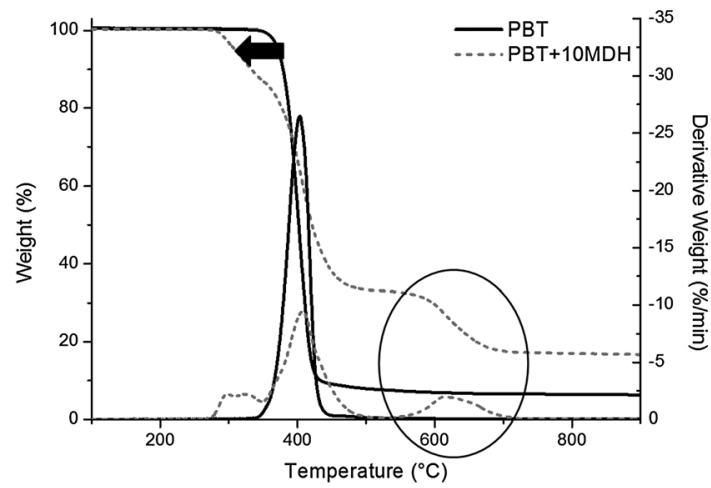

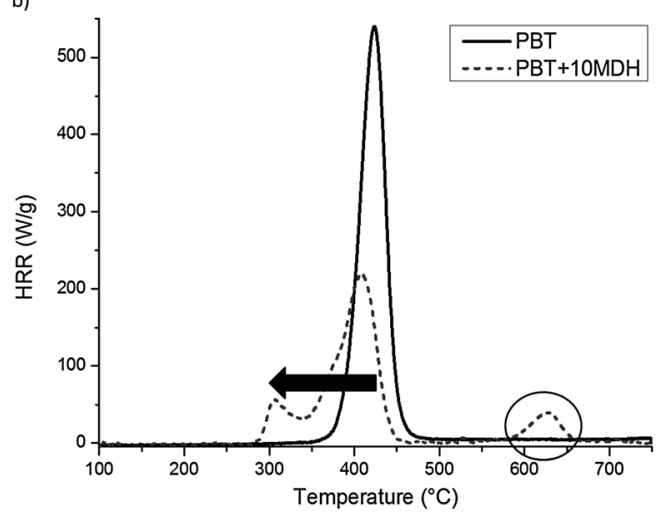

Figure 2. (a) Weight (\%) and derivative weight (\%/min) versus temperature with heating rate $\beta=10{ }^{\circ} \mathrm{C} / \mathrm{min}$ obtained by thermogravimetric analyses under nitrogen atmosphere for PBT with and without $10 \mathrm{wt} . \%$ of MDH. (b) HRR (W/g) versus temperature obtained by PCFC analyses with a heating rate of $\beta=1{ }^{\circ} \mathrm{C} / \mathrm{s}$ under nitrogen atmosphere for PBT with and without 10wt.\% of $\mathrm{MDH}$.

a)

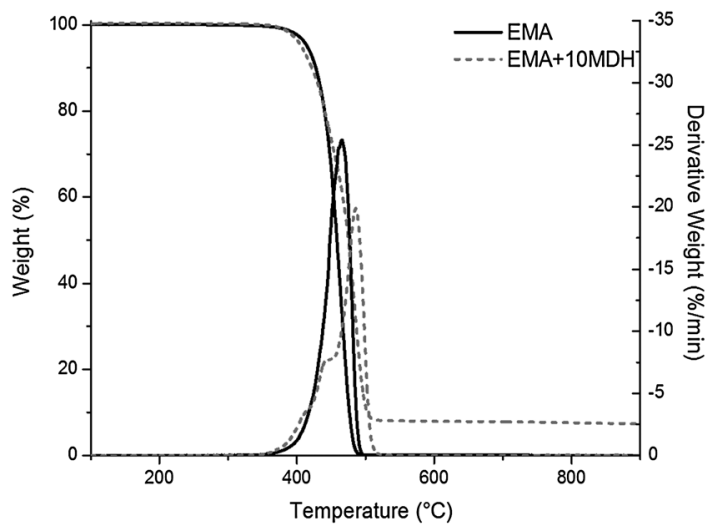

b)

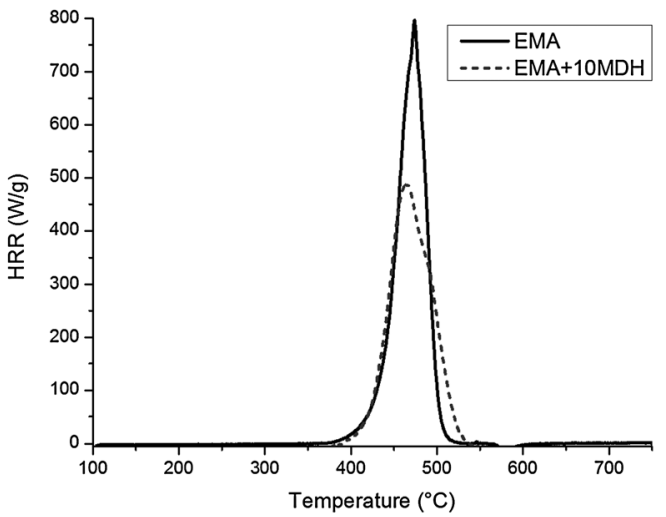

Figure 3. (a) Weight (\%) and derivative weight (\%/min) versus temperature with heating rate $\beta=10^{\circ} \mathrm{C} / \mathrm{min}$ obtained by thermogravimetric analyses under nitrogen atmosphere for EMA with and without $10 \mathrm{wt} \%$ of MDH. (b) HRR (W/g) versus temperature obtained by PCFC analyses with a heating rate of $\beta=1{ }^{\circ} \mathrm{C} / \mathrm{s}$ under nitrogen atmosphere for EMA with and without 10wt.\% of MDH.

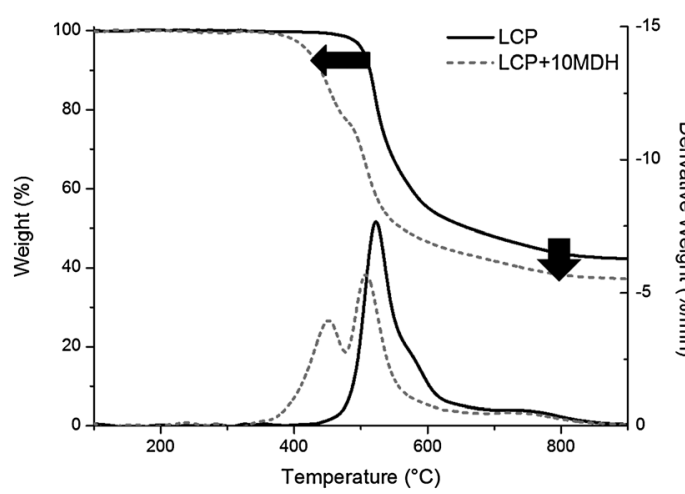

b)

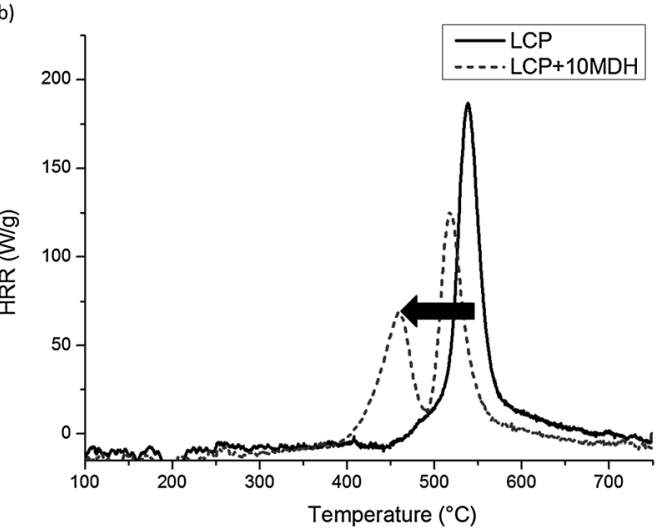

Figure 4. (a) Weight (\%) and derivative weight (\%/min) versus temperature with heating rate $\beta=10{ }^{\circ} \mathrm{C} / \mathrm{min}$ obtained by thermogravimetric analyses under nitrogen atmosphere for LCP with and without $10 \mathrm{wt}$. $\%$ of MDH. (b) HRR (W/g) versus temperature obtained by PCFC analyses with a heating rate of $\beta=1{ }^{\circ} \mathrm{C} / \mathrm{s}$ under nitrogen atmosphere for LCP with and without 10wt.\% of MDH. 
noticed from thermogravimetric curves) of these materials corresponds not only to the water release from MDH but also to the pyrolysis of the polymers.

Pure PLA (series A) exhibits only one peak of degradation centered on $390^{\circ} \mathrm{C}$ (Figure $1(\mathrm{a})$ ). When it is filled with $\mathrm{MDH}$, the degradation occurs in several steps. The main peak of degradation of PLA $\left(380^{\circ} \mathrm{C}\right)$ vanishes (only a very small peak is also observed at $350^{\circ} \mathrm{C}$ ), and the polymer degrades almost completely at lower temperature $\left(300^{\circ} \mathrm{C}\right)$. The first peak is detected much earlier (the first peak at $280^{\circ} \mathrm{C}$ ). The two first peaks in the range $270-350^{\circ} \mathrm{C}$ correspond not only to water release from MDH decomposition but also to early pyrolysis of PLA (as confirmed by the presence of a peak of HRR in the same range in PCFC - Figure 1(b)). PLA is very sensitive to hydrolysis at high temperature. Therefore, the release of water from the decomposition of MDH leads to its quick degradation.

The last peak is observed at higher temperature $\left(450-500^{\circ} \mathrm{C}\right)$ when PLA is filled with MDH. PCFC curve (Figure 1(b)) confirms that it corresponds to the release of combustible gases. This peak can be assigned to the degradation of an organic residue that will be called char in the following. Therefore, it can be assumed that MDH promotes charring, but the thermal stability of this char is low according to its decomposition temperature.

Polybutylene terephtalate (series B) is also very sensitive to hydrolysis, and its degradation also occurs earlier in the presence of MDH (Figure 2(a)). Nevertheless, the main peak is still observed at the same temperature as for pure PBT (approximately $400^{\circ} \mathrm{C}$ ). Like PLA, PBT filled with MDH exhibits an additional step of degradation at high temperature, indicating that MDH also promotes charring of aromatic polyesters. However, its temperature of degradation is significantly higher $\left(600^{\circ} \mathrm{C}\right)$. Such observation is particularly interesting while the temperature in the condensed phase could reach $500-700^{\circ} \mathrm{C}$ during a fire (e.g., in the cone calorimeter test, according to the heat flux [25]). HRR curve (Figure 2(b)) is perfectly in accordance with TGA.

On the contrary, when EMA (series C) is filled with MDH, there is no important change of the degradation pathway. The degradation occurs in one main step with and without MDH (a small shoulder is observed at low temperature for EMA filled with MDH). Peak of mass loss rate is slightly shifted to higher temperature, probably due to endothermic effect related to the water release when $\mathrm{MDH}$ is decomposed (from $350{ }^{\circ} \mathrm{C}$ ). Its value decreases slightly from 25 to $20 \% / \mathrm{min}$. A shoulder is also observed at lower temperature. No char is observed.

Similarly, the temperature of the peak of HRR is not significantly modified (Figure 3(b)). The intensity of the peak is lowered, probably as a result of the endothermic effect of water release, which slows down the pyrolysis of the polymer.

A significant decrease of the thermal stability is observed when MDH is added to LCP (series D). The incorporation of MDH leads to a first peak of mass loss rate at low temperature $\left(450^{\circ} \mathrm{C}\right)$ while pure LCP starts degrading at $480^{\circ} \mathrm{C}$ with a peak of mass loss rate close to $540^{\circ} \mathrm{C}$ (Figure 4 (a)). Moreover, the final residue is lowered in the presence of MDH (43 and 37\% for pristine LCP and LCP filled with MDH, respectively).

The incorporation of MDH into LCP also leads not only to a peak of HRR at lower temperature but also to a slight increase in Total Heat Release (from about 7 to $8 \mathrm{~kJ} / \mathrm{g}$ - Figure 4(b)). This could be assigned to the decrease in char content due to MDH: A higher content of fuels is released in gas phase.

Figures 5 and 6 summarize the results for all formulations to establish some relations between the chemical structure of polymers and the MDH influence on the thermal stability. Figure 5 plots the onset temperature of degradation for the filled polymers versus the pure ones. It has been previously explained that the onset temperature of degradation in TGA could be due to the mass loss of the polymer or alternatively of the MDH. Therefore, the onset temperature in PCFC was preferentially considered. This temperature corresponds to an arbitrary HRR of $30 \mathrm{~W} / \mathrm{g}$, which ensures that the polymer has started degrading at this temperature.

All polymers from series A, B, and D exhibit a lower onset temperature when they are filled with $10 \mathrm{wt} . \%$ of MDH. This result tends to prove the role of the water released from MDH in promoting the hydrolytic degradation of the polymers at high temperature. Most of these polymers exhibit a decrease in onset temperature higher than $50{ }^{\circ} \mathrm{C}$. PHB and PHBV are highly sensitive to hydrolysis, but the decrease in their onset temperatures is quite limited $\left(10-25^{\circ} \mathrm{C}\right)$. Pure PHB and PHBV degrade at low temperature (from $275^{\circ} \mathrm{C}$ ). Their stability is only slightly disturbed by the water release from $\mathrm{MDH}$. 


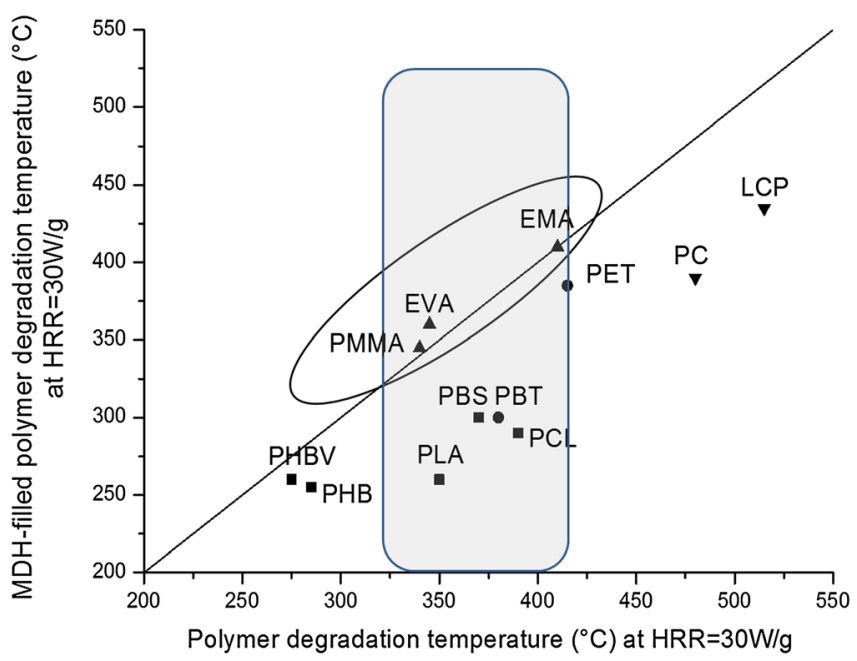

Figure 5. Onset temperature of degradation for MDH-filled polymers versus polymer degradation temperature for pure polymers (the shaded area corresponds to the temperature range of MDH decomposition).

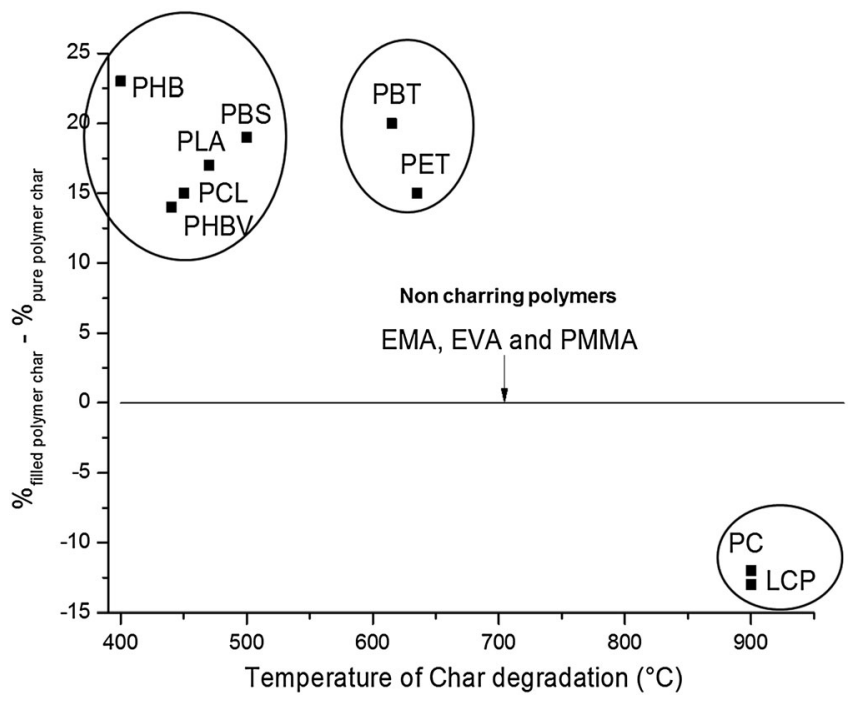

Figure 6. Char promotion versus its degradation temperature.

On the contrary, polymers from series $\mathrm{C}$ exhibit similar onset temperatures with and without MDH. These polymers seem to be not sensitive to hydrolysis.

Char promotion and its thermal stability are other important parameters. Figure 6 plots the char promotion versus its degradation temperature. Char promotion corresponds to the difference between the char content for polymers filled with $\mathrm{MDH}$ and for pure polymers. The mineral fraction of the residue (6.9wt.\% due to $\mathrm{MgO}$ ) is not considered to calculate the char content. For series A and $\mathrm{B}$, the char percentage was calculated from the mass loss at high temperature. For series D, the char was calculated using the value of residual mass at $900^{\circ} \mathrm{C}$ because this char is still thermally stable at this temperature.

Four groups (corresponding to the four series) could be identified. For series $\mathrm{C}$, no char was formed in presence of $\mathrm{MDH}$. For series $\mathrm{D}$, the $\mathrm{MDH}$ is not a charring promoter but a charring inhibitor because the char content is lower in the presence of MDH for these polymers. MDH exhibits a significant char promotion effect for polymers from series A and B. The increase of char content is in the range 14$23 \mathrm{wt} . \%$ for these polymers. However, a significant difference could be noticed from the temperature of the char degradation: The char is much more thermally stable for aromatic polyesters (series B) 
than for aliphatic polyesters (series A). Its degradation temperature is in the ranges $600-650{ }^{\circ} \mathrm{C}$ and $400-500{ }^{\circ} \mathrm{C}$ for series B and A, respectively.

The thermal degradation has been also studied by Py-GC/MS analysis. The chromatograms obtained at a pyrolysis temperature of $900{ }^{\circ} \mathrm{C}$ for the four polymers representative of series $\mathrm{A}, \mathrm{B}, \mathrm{C}$, and D are shown in Figure 7. PLA (from series A) and, to a less extent, PBT (from series B) exhibit a significantly different chromatogram when they are filled with MDH. On the contrary, chromatograms of EMA and LCP (from series $\mathrm{C}$ and $\mathrm{D}$, respectively) are very similar with and without $\mathrm{MDH}$.

According to the literature [26-29], PLA pyrolysis is initiated by cis-elimination and transesterification. The main products obtained [28] are isomers of lactide (DL-lactide and meso-lactide) and volatile products such as $\mathrm{CO}, \mathrm{CO}$, acetaldehyde, and acrylic acid. For a pyrolysis at $900^{\circ} \mathrm{C}$,

a)
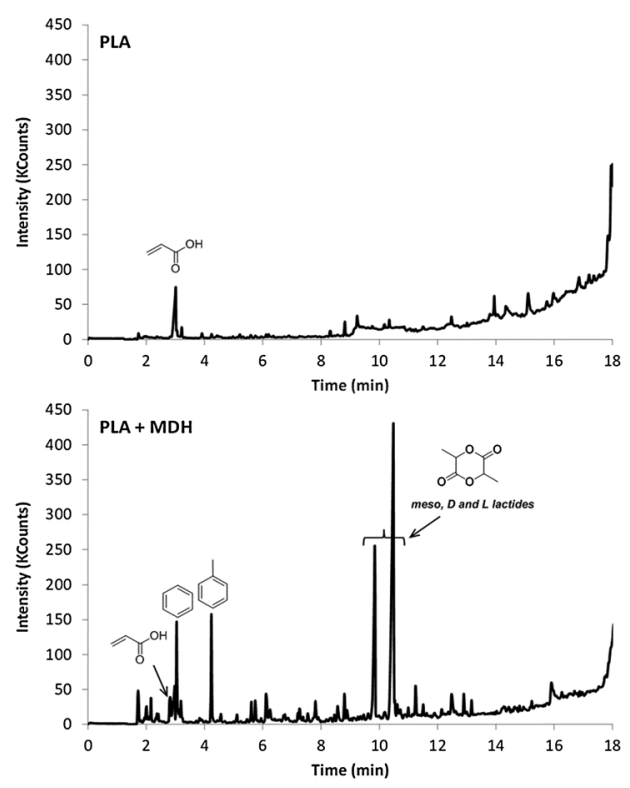

c)
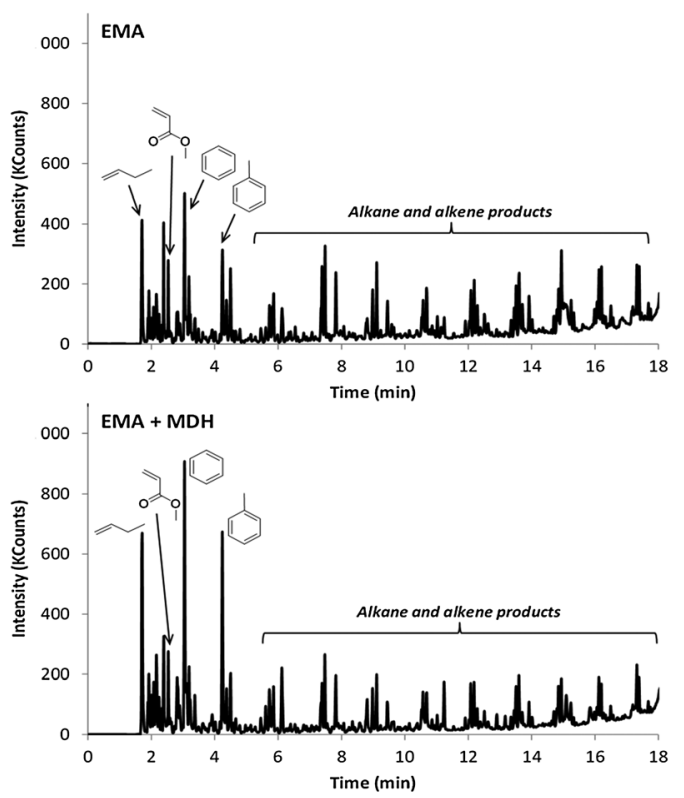

b)
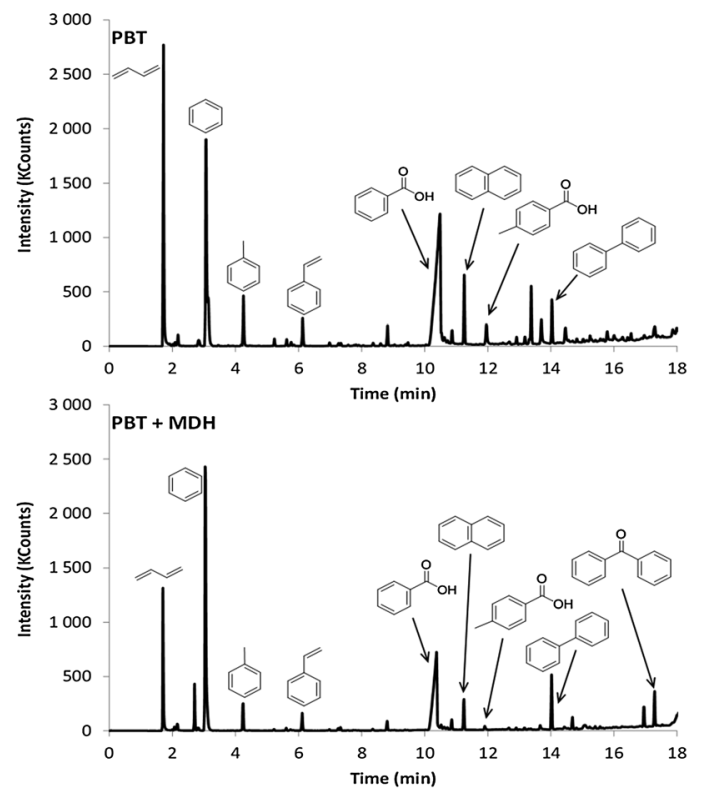

d)
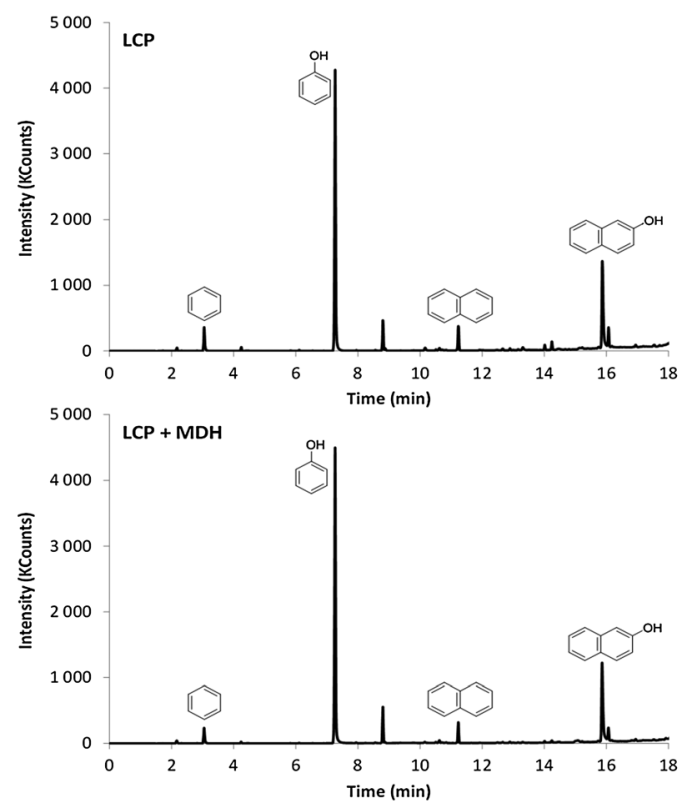

Figure 7. Py-GC/MS chromatograms of (a) PLA, PLA/MDH; (b) PBT, PBT/MDH; (c) EMA, EMA/MDH; and (d) LCP and LCP/MDH samples. 
the chromatogram of PLA shows essentially the formation of acrylic acid (peak at $2.9 \mathrm{~min}$ ). In presence of $\mathrm{MDH}$, the thermal degradation of PLA changes, and various new peaks are observed on the chromatogram. The presence of lactide (two peaks at 9.8 and 10.4 min corresponding to meso, D and L compounds), acrylic acid (peak at $2.9 \mathrm{~min}$ ), and aromatic compounds (benzene and toluene at 3 and 4.2 min, respectively) can be noted.

Concerning the degradation of PBT, the appearance (at $2.7 \mathrm{~min}$ ) and disappearance (at 13.4 and $13.7 \mathrm{~min}$ ) of small peaks and evolution of intensities of some signals can be remarked when MDH was added. The most intense peaks correspond to aromatic compounds (derivatives of benzene and benzoic acid, etc.) and butadiene (peak at $1.7 \mathrm{~min}$ ). The degradation of unfilled and filled PBT will be discussed in more detail later.

The chromatogram obtained for EMA corresponds to that described in the literature [30]. Indeed, characteristic products of degradation of both parts of the copolymer (ethylene and methyl acrylate parts) were observed. The chromatogram shows the presence of methylacrylate and alkyl and alkene compounds. The presence of MDH does not affect the thermal degradation of EMA during the pyrolysis step of Py-GC/MS analysis.

The analysis of the LCP sample showed mainly the formation of phenol. Some small peaks attributed to aromatic compounds were also observed. Sato et al. [31] studied the thermal degradation of the same LCP compound (Vectra A950), and they described that the main evolved gaseous products resulting from thermal degradation are $\mathrm{H}_{2} \mathrm{O}, \mathrm{CO}, \mathrm{CO}_{2}$, and phenol (phenol was released from the PHB moiety). In their study, other minor components were also detected (benzene, benzoic acid, naphthalene, etc.). As for EMA, the presence of MDH does not affect the thermal degradation of LCP during the pyrolysis step of Py-GC/MS analysis.

To conclude, it was highlighted that hydrolysis and char formation in presence of MDH as well as the char stability and the nature of the released gases are dependent on the polyester structure. It was shown that MDH can be a good char promoter for PBT and PET (aromatic polyesters from series B). Indeed, the hydrolysis of these polymers appears limited in comparison to aliphatic polyesters as PLA. The char amount is relatively high (20wt.\% for PBT) and relatively thermally stable up to around $700{ }^{\circ} \mathrm{C}$. It could be reasonably assumed that the char degradation temperature is higher and its protective effect is stronger. Therefore, in the following, the effect of MDH on the thermal stability and the flammability of PBT has been evaluated in details.

\subsection{Effect of $M D H$ on the thermal degradation and flammability of PBT}

In the first part of this study, the MDH has been identified as a charring promoter for some polyesters, particularly for PBT. Formulations based on PBT filled with various MDH content were prepared and studied by TGA and PCFC to optimize the char promotion. Figure 8(a) shows the mass loss rate and HRR measured using TGA and PCFC for pristine PBT and PBT filled with MDH. As noticed previously, the degradation of PBT occurs in one single step (peak of heat release rate (pHRR) at $400^{\circ} \mathrm{C}$ ), whereas PBT filled MDH exhibits three steps: The first one (at $310^{\circ} \mathrm{C}$ ) is related to the early degradation of $\mathrm{PBT}$ due to its hydrolysis by water, the second step $\left(\right.$ at $400{ }^{\circ} \mathrm{C}$ ) corresponds to the main degradation peak of PBT, and the third step (at $640^{\circ} \mathrm{C}$ ) corresponds to the degradation of the char. Another significant parameter in fire reaction is the effective heat of combustion (EHC). This parameter is calculated as the ratio between the total heat release (THR) measured in PCFC and the mass loss fraction measured in TGA. EHC was calculated for the whole degradation and separately for the first degradation steps (called step A and corresponding to the sum of the first step and the main degradation step in Figure 8(a)) and for the last degradation step (called step B and corresponding to the degradation of the char). The EHC values for pure PBT and PBT filled with 10 wt.\% of MDH are given in Table III. The EHC of step A for PBT filled with MDH is equal to $21.1 \mathrm{~kJ} / \mathrm{g}$. This value is very close to the value obtained for pure PBT. On the contrary, the EHC of step B for PBT filled MDH is much lower $(12 \mathrm{~kJ} / \mathrm{g})$. Figure 8 (b) shows also the change in the EHC values according to the MDH content, from 10 to $40 \mathrm{wt} . \%$. The EHC of step B does not change when increasing the MDH content. Therefore, the composition of the char could be assumed constant whatever the MDH content. Despite the scattering of results, it could be observed that the EHC of step A decreases slightly as a result of the dilution of fuel gases by water released during 
a)

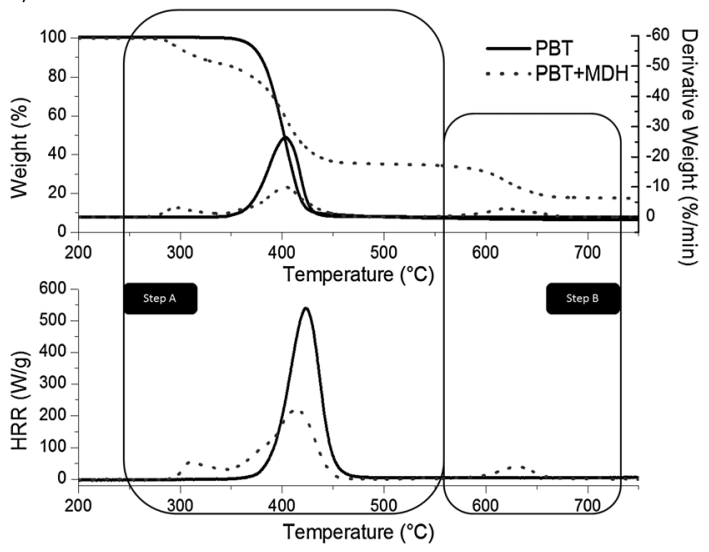

b)

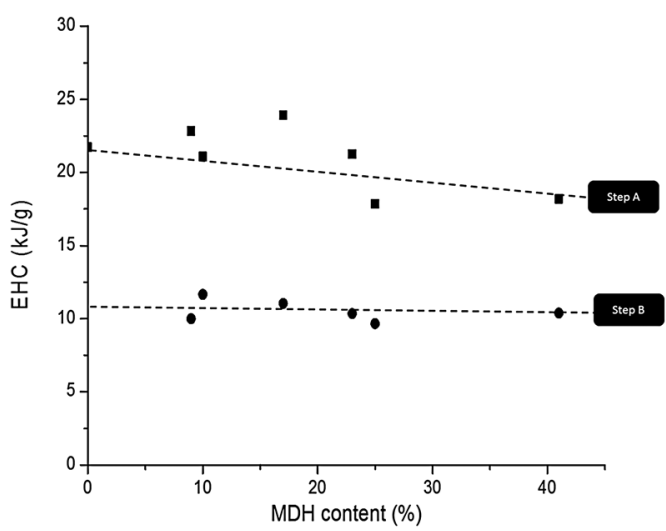

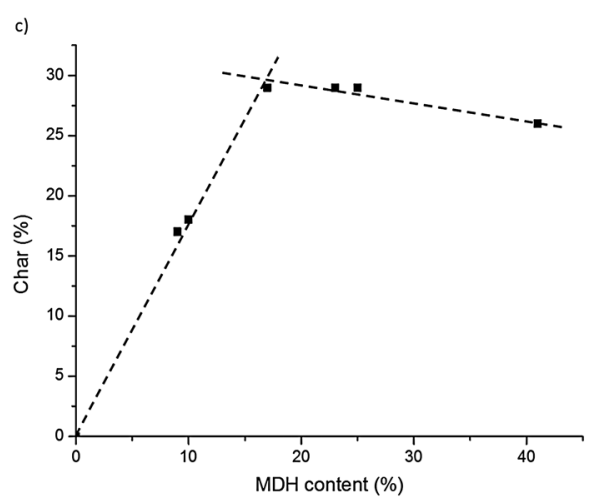

Figure 8. PCFC and TGA curves for (a) pure PBT and PBT filled with 10wt.\% of MDH, (b) EHC versus MDH content in PBT filled with MDH, and (c) char yield versus MDH content in PBT filled with MDH (c).

Table III. Mass loss, total heat release, and effective heat of combustion for pure PBT and PBT filled with $10 \mathrm{wt} . \%$ of $\mathrm{MDH}$.

\begin{tabular}{lccc}
\hline & Mass loss $(\%)$ & THR $(\mathrm{kJ} / \mathrm{g})$ & EHC $=$ THR/ML $(\mathrm{kJ} / \mathrm{g})$ \\
\hline PBT & 93 & 20.2 & 21.7 \\
PBT $+\mathrm{MDH}\{$ Step A & 65 & 13.7 & 21.1 \\
& 17 & 2.1 & 12.4 \\
\hline
\end{tabular}

MDH decomposition. Figure 8(c) shows the char content according to the MDH content. The char content increases up to almost 30wt.\% when increasing MDH content. Nevertheless, above a threshold value around $17 \mathrm{wt} . \%$ of $\mathrm{MDH}$, the char content levels off and starts decreasing at MDH content higher than $25 \mathrm{wt} . \%$. It means that the char promotion could be one of the main modes-ofaction of MDH at low or moderate MDH content. At higher MDH content, this effect is probably lesser in comparison with the other modes-of-action (dilution of condensed phase, endothermic effect, and dilution of fuel gases).

\subsection{Thermal degradation and flammability of $M D H$-filled and $M g O$-filled PBTs}

Magnesium dihydroxide not only promotes the charring of PBT but also leads to its early degradation by hydrolysis. If charring and hydrolysis are two decoupled phenomena, $\mathrm{MgO}$ could exhibit char promotion effect without hydrolysis. PBT formulations filled with $10 \mathrm{wt} . \%$ of $\mathrm{MDH}$ or $\mathrm{MgO}$ were studied using TGA, PCFC, TGA-FTIR, and Py-GC/MS to compare both fillers as char promoters.

The thermal degradation of PBT starts earlier with $\mathrm{MDH}$ than with $\mathrm{MgO}$, as shown in Figure 9. The onset temperature in PCFC is 370 and $300^{\circ} \mathrm{C}$ for PBT and MgO-filled PBT and MDH-filled PBT, 


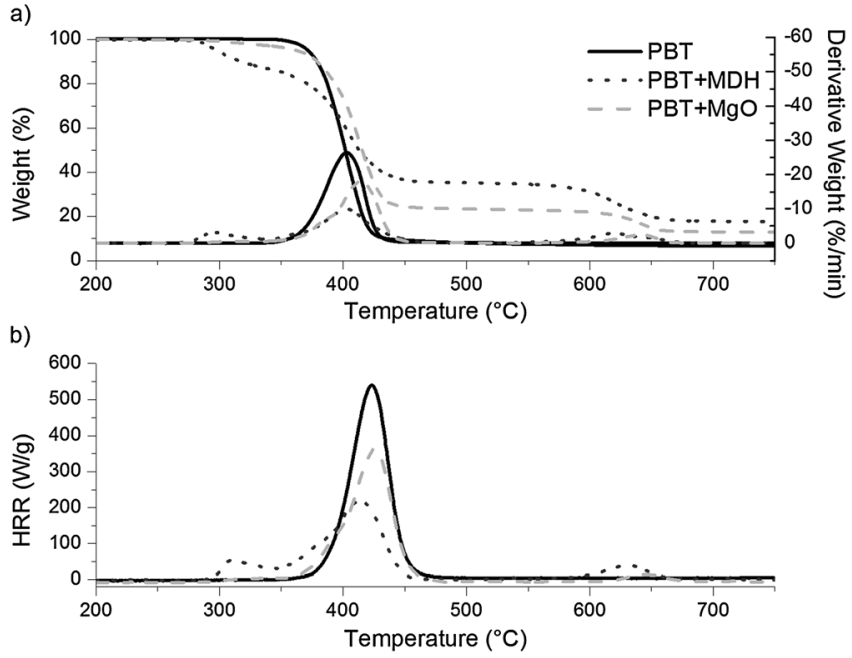

Figure 9. (a) Thermal stability in TGA $\left(10^{\circ} \mathrm{C} / \mathrm{min}, 50-900{ }^{\circ} \mathrm{C}\right.$ under $\left.\mathrm{N}_{2}\right)$ and (b) flammability in $\left(1{ }^{\circ} \mathrm{C} / \mathrm{min}\right.$, $50-750{ }^{\circ} \mathrm{C}$ under $\mathrm{N}_{2}$, and $900^{\circ} \mathrm{C}$ under $\mathrm{O}_{2}$ ) for pure PBT, MDH-filled PBT, and MgO-filled PBT.

respectively. The peak at low temperature on thermogravimetric or HRR curves for PBT filled with $\mathrm{MDH}$ is not observed for PBT filled with $\mathrm{MgO}$. Therefore, it could be assumed that there is no hydrolytic degradation of PBT in the presence of $\mathrm{MgO}$. The main peak at $400-450{ }^{\circ} \mathrm{C}$ is significantly reduced in the presence of $\mathrm{MDH}$ and $\mathrm{MgO}$, indicating a lower flammability. However, the decrease of pHRR is more pronounced with MDH probably because a part of the polymer is already decomposed at lower temperature in this case.

A peak of mass loss rate (and HRR) could be detected at high temperature for MDH-filled and $\mathrm{MgO}$-filled PBTs. Therefore, $\mathrm{MgO}$ promotes charring as $\mathrm{MDH}$, but the char content is significantly lower $(10 \mathrm{wt} . \%$ versus $17 \mathrm{wt} . \%)$. However, because the particle size could affect the charring promotion, it should be noticed that both studied fillers exhibit very different particle size. The thermal stability of both chars is similar; their degradation temperatures are in the range $600-650{ }^{\circ} \mathrm{C}$.

Magnesium dihydroxide and $\mathrm{MgO}$ are efficient char promoter for PBT. A stable char is formed, and it degrades at high temperature (in the range $600-650^{\circ} \mathrm{C}$ ) under non-oxidizing atmosphere. TGA in nitrogen flow of PBT filled with $\mathrm{MDH}$ and $\mathrm{MgO}$ was stopped at $550{ }^{\circ} \mathrm{C}$, and the residue was kept to be further analyzed by FTIR spectroscopy. A significant difference at macroscopic scale is observed between both residues; it is intumescent only for PBT filled with MDH probably because of the water release from the hydrated filler.

As an example, Figure 10 shows the FTIR spectrum of the residue obtained from PBT-MgO pyrolysis (the FTIR spectrum is the same for PBT-MDH). Carboxylate functions (asymmetric and symmetric modes are located at 1580 and $1400 \mathrm{~cm}^{-1}$, respectively) are identified. Two large absorption bands at 3300 and at $550 \mathrm{~cm}^{-1}$ could be attributed to water and $\mathrm{MgO}$, respectively. Another band at $720 \mathrm{~cm}^{-1}$ is observed, but it was not attributed.

The EDX analyses indicate similar elementary percentages for both residues. Three main elements were found: C, O, and $\mathrm{Mg}$, whose mass and molar percentages are reported in Table IV. Significant C percentage is observed, confirming the organo-mineral feature of the residue. The O percentage is too high to correspond only to the oxygen in $\mathrm{MgO}$. The excess of $\mathrm{O}$ could be attributed to carboxylate groups, detected by FTIR analyses.

The thermal decomposition of PBT has been widely studied by TGA-FTIR [32, 33] or Py-GC/MS $[34,35]$. The degradation of PBT during pyrolysis is initiated by random scissions of the ester bonds [36]. The scission is achieved through a six-member cyclic transition state to obtain alkenyl and carboxyl end groups. The main product of the PBT degradation is butadiene, but tetrahydrofuran (THF) is also released. The scission of the $\mathrm{C}-\mathrm{O}$ ester bond and intra-molecular or inter-molecular hydrogen transfer lead to the formation of terminal hydroxyl compounds such as 1,4-butanediol, which leads to THF through an acid-catalyzed dehydration reaction [35]. The formation of water during the decomposition of the polymer contributes to the acid catalyzed hydrolysis of the ester 


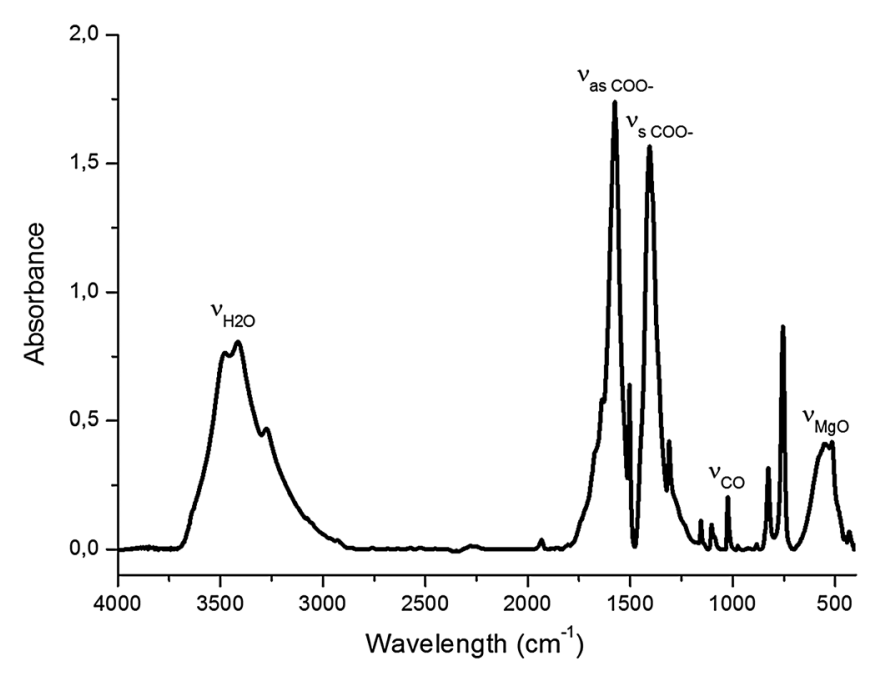

Figure 10. FTIR spectrum of PBT-MgO residue.

Table IV. EDX results for PBT-MDH and PBT-MgO residues.

\begin{tabular}{|c|c|c|c|c|c|c|c|}
\hline & \multicolumn{3}{|c|}{$\%$ mass } & \multicolumn{3}{|c|}{$\%$ molar } & \multirow[b]{2}{*}{$\%$ char } \\
\hline & $\mathrm{C}$ & $\mathrm{O}$ & $\mathrm{Mg}$ & $\mathrm{C}$ & $\mathrm{O}$ & $\mathrm{Mg}$ & \\
\hline PBT-MDH & $43.2 \pm 0.4$ & $46.9 \pm 0.4$ & $9.9 \pm 0.06$ & $51.9 \pm 0.4$ & $42.2 \pm 0.4$ & $5.9 \pm 0.03$ & 28 \\
\hline PBT-MgO & $44.2 \pm 0.5$ & $45.2 \pm 0.4$ & $10.6 \pm 0.2$ & $53.0 \pm 0.5$ & $40.7 \pm 0.4$ & $6.3 \pm 0.1$ & 13 \\
\hline
\end{tabular}

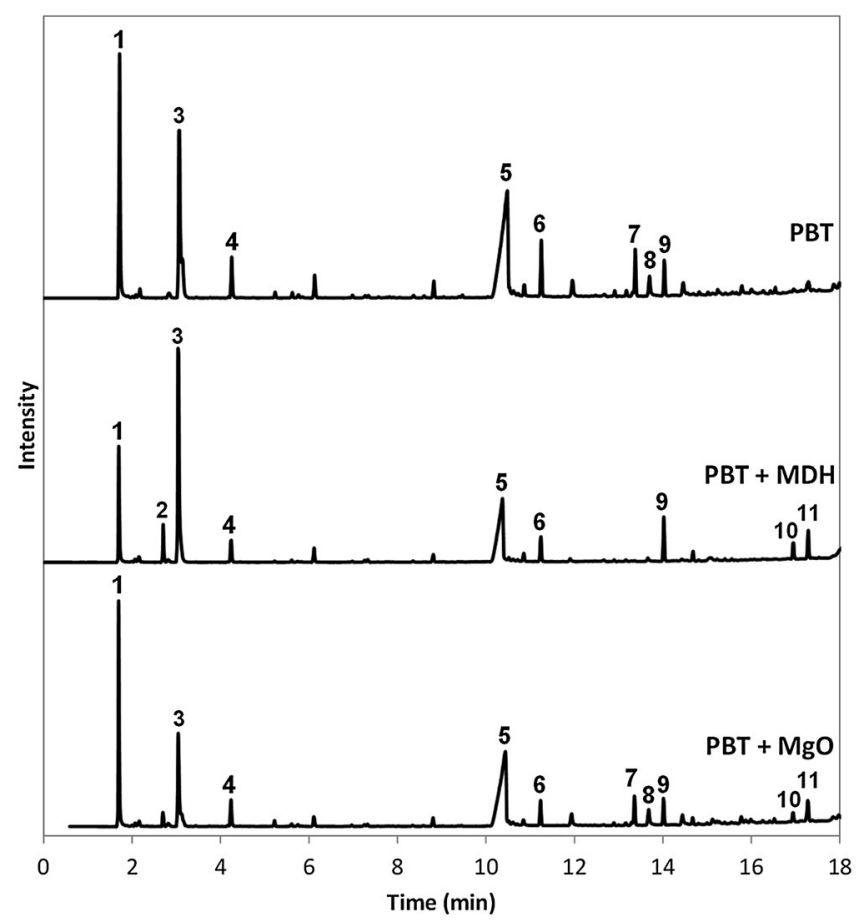

Figure 11. Chromatograms obtained by GC/MS-pyrolysis at flash temperature $\left(T_{\text {flash }}=900{ }^{\circ} \mathrm{C}\right)$ for pure PBT (top), MDH-filled PBT (middle) and MgO-filled PBT (bottom). 
groups and to the release of THF [37]. The decomposition starts from successive scissions of $\mathrm{C}-\mathrm{O}$ alkyl or acyl groups to form products with vinyl, carboxylic, aldehyde, or hydroxyl functions. The products functionalized with carboxylic groups are converted at high temperature by $\mathrm{CO}_{2}$ elimination, into more stable compounds [38] such as benzene or naphthalene.

The Py-GC/MS (Figure 11) and the TGA/FTIR (Figure 12) analyses show significant differences between pure PBT, MDH-filled PBT, and MgO-filled PBT. The Py-GC/MS chromatograms at $900{ }^{\circ} \mathrm{C}$ for the three samples show the presence of butadiene, benzene, benzoic acid, naphthalene, and diphenyl
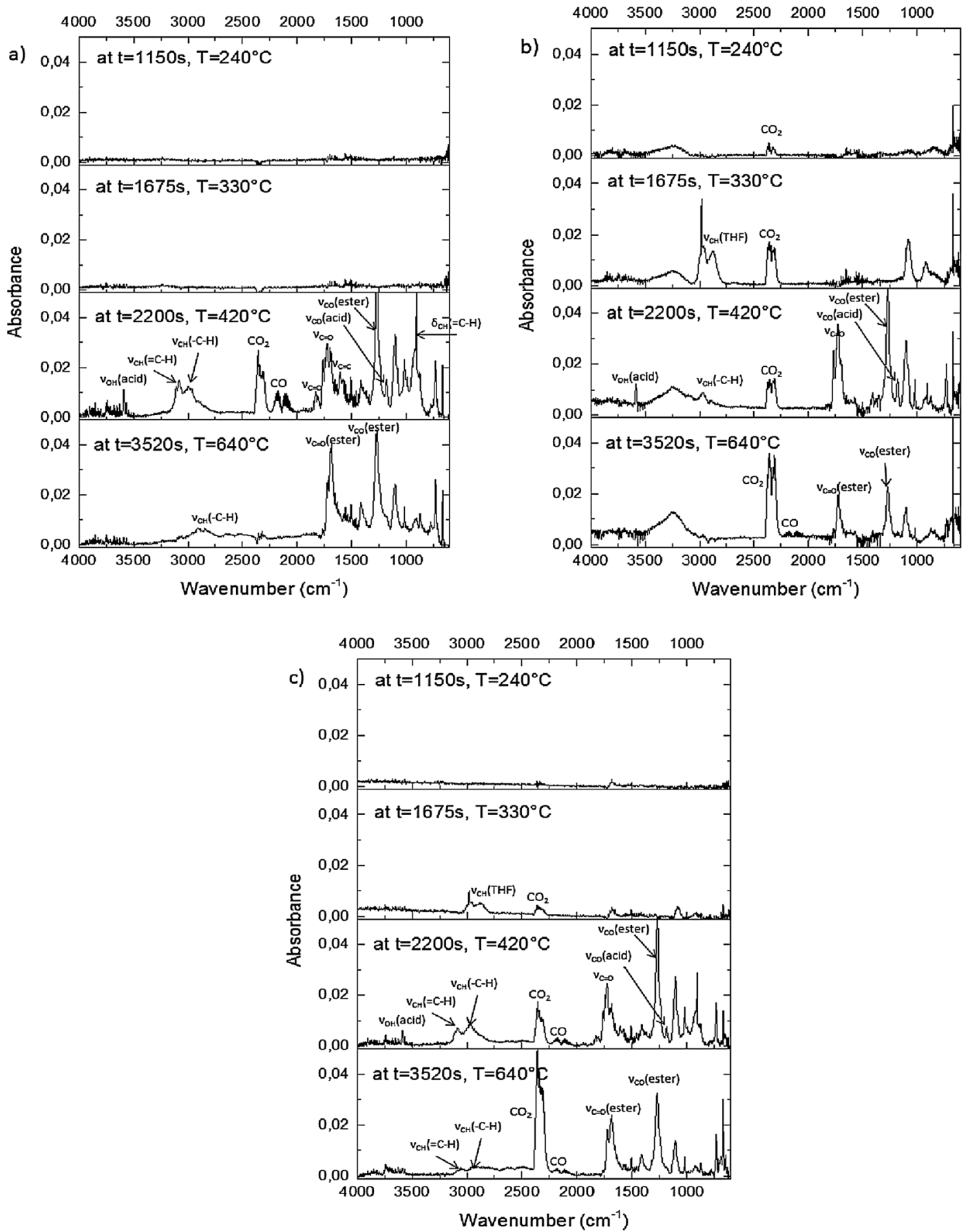

Figure 12. FTIR spectra obtained by TGA-FTIR at different temperatures $\left(240,330,420\right.$, and $\left.640{ }^{\circ} \mathrm{C}\right)$ for (a) pure PBT, (b) PBT/MDH, and (c) and PBT/MgO. 
(peaks 1, 3, 5, 6, and 9 on chromatograms, respectively). However, the ratios of peak heights are different for these different samples. This reflects a difference of degradation of these PBT composites during pyrolysis. The chromatogram of PBT filled with MDH is significantly different (with a decrease in peaks 1 and 5 and an increase of peaks 2 and 9), whereas the chromatograms of PBT and PBT filled with $\mathrm{MgO}$ exhibit similar patterns. This observation shows that water release from MDH decomposition influences the degradation pathway of PBT and changes the ratios of pyrolytic products. It must be noticed that some other components were not identified (peaks 2, 4, 7, 8, 10, and 11).

The TGA/FTIR analyses have also highlighted differences during the thermal decomposition of pure PBT and MDH-filled or MgO-filled PBT. The results are summarized in Figure 12. The FTIR spectra recorded at different temperatures show differences in terms of decomposition for the three samples.

The degradation of pure PBT, at $420^{\circ} \mathrm{C}$ (Figure 12(a)) during the maximum of decomposition of PBT, releases butadiene, benzoic acid, butyl benzoate, $\mathrm{CO}_{2}$, and $\mathrm{CO}$ as main volatile decomposition products in accordance with the literature [32].

Magnesium dihydroxide or $\mathrm{MgO}$ modifies the $\mathrm{PBT}$ decomposition pathway below $420^{\circ} \mathrm{C}$. In comparison with pure PBT, an earlier release of $\mathrm{CO}_{2}$ is observed from $240^{\circ} \mathrm{C}$ for $\mathrm{MDH}$-filled PBT and $330^{\circ} \mathrm{C}$ for $\mathrm{MgO}$-filled $\mathrm{PBT}$. The presence of $\mathrm{MDH}$ leads to an early extensive hydrolytic degradation of PBT due to the water release from the filler. However, in both cases, we can observe a significant release of THF from $330^{\circ} \mathrm{C}$, which is more important for $\mathrm{MDH}$-filled PBT. The THF formation is the consequence of the ring formation reaction from butanediol, which is formed by hydrolytic ester bond scission [33,37]. Moreover, in the presence of basic Mg ions, the formation of terephthalate salts is preferred against the terephthalic acid formation. The hydrolytic bond scission is enhanced by the water release of $\mathrm{MDH}$. Above $420^{\circ} \mathrm{C}$, the degradation pathway seems very close to pure PBT with the presence of benzoic acid, butyl benzoate, $\mathrm{CO}_{2}$, and $\mathrm{CO}$ except butadiene (this identification is not obvious).

We must emphasize that an important release of $\mathrm{CO}$ and $\mathrm{CO}_{2}$ is still observable at $640{ }^{\circ} \mathrm{C}$ for MDHfilled and MgO-filled PBTs. This release at high temperature in the presence of $\mathrm{MDH}$ and $\mathrm{MgO}$ is due to the char decomposition. This char stable at high temperature results from the terephthalate salts formation.

The results obtained by Py-GC/MS and TGA/FTIR are complementary and allow to draw conclusions about the nature and the release temperature of pyrolysis gases. The release of water due to MDH led to change the decomposition mechanism of PBT with lower release temperatures of volatile compounds such as THF and $\mathrm{CO}_{2}$. Moreover, the addition of $\mathrm{MgO}$ unlike $\mathrm{MDH}$ does not seem to affect the nature of PBT decomposition gases, except that the degradation of char led to the release of $\mathrm{CO}_{2}$ at higher temperature $\left(\mathrm{CO}_{2}\right.$ is still present at $640^{\circ} \mathrm{C}$ for $\mathrm{MDH}$-filled or MgO-filled PBT).

\subsection{Cone calorimeter tests}

The main objective of this article is to evaluate the char promotion of MDH into polyesters and especially into PBT mainly from TGA and PCFC results. It is well known that the flame retardancy could not be evaluated properly using microscale analyses. It is beyond the scope of this article to establish the relations between PCFC and other tests. Such analyses could be found elsewhere [39, 40].

Nevertheless, it is of great interest to check if the selected system PBT-MDH could exhibit significant flame retardancy in the cone calorimeter test. Pure PBT and PBT filled with 10 and $25 \mathrm{wt} . \%$ of MDH were tested at an irradiance of $50 \mathrm{~kW} / \mathrm{m}^{2}$ (Figure 13). At these low or moderate MDH contents, main modes-of-action of MDH (as dilution of organic phase, endothermic effect, and dilution of fuels by water) are believed to be none or poorly efficient.

However, the incorporation of MDH leads to a significant decrease in pHRR (from about 1000 to less than $300 \mathrm{~kW} / \mathrm{m}^{2}$ with only $10 \mathrm{wt} . \%$ of $\mathrm{MDH}$, i.e., a decrease of $75 \%$ ). The curve shape also changes: Pure PBT exhibits a typical thermally thin behavior, whereas filled PBT exhibits a thermally thick charring behavior confirming the barrier effect of the organo-mineral layer formed on the sample surface. PBT burns approximately in $300 \mathrm{~s}$. On the contrary, filled PBT is not fully degraded after $1200 \mathrm{~s}$. Intumescence and presence of char at the end of the test are observed for filled PBT. Finally, ignition occurs earlier when MDH is added into PBT (32s for filled PBT vs. 40 s for pure PBT). 


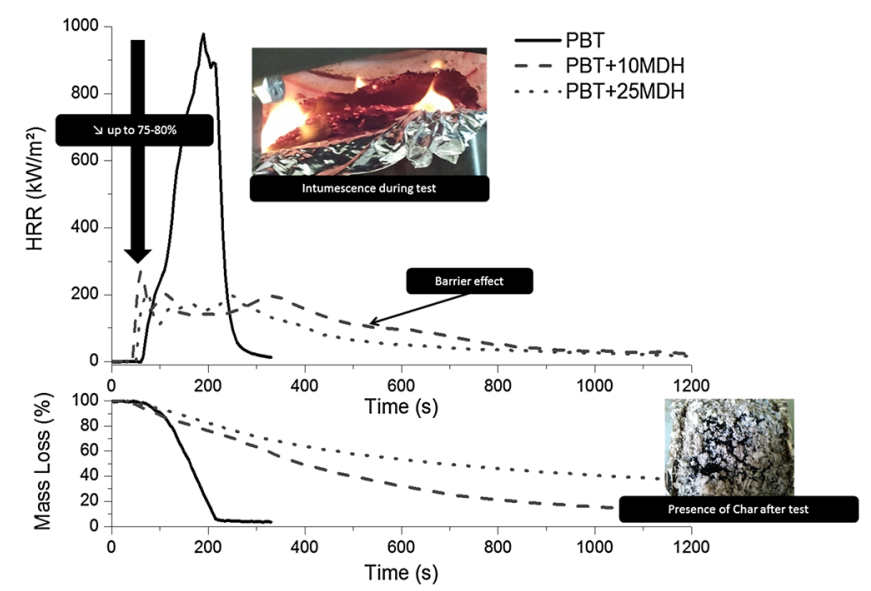

Figure 13. Cone calorimeter tests for pure PBT and MDH-filled PBT (irradiance $50 \mathrm{~kW} / \mathrm{m}^{2}$ ).

These observations (charring and early ignition due to hydrolysis) seem to be in good agreement with microscale analyses.

\section{CONCLUSION}

Magnesium dihydroxide was investigated as a char promoter in various polyesters using microscale analytical methods. Relationships between its presence and the chemical structure of the polyesters were studied. Aromatic groups in the polymer backbone allow significant charring with a high thermally stable char. Aliphatic polyesters also show charring, but the char exhibits poor thermal stability. The decomposition of polymers with pendant ester groups are not affected by the presence of MDH. Finally, MDH is detrimental for highly charring polymers as PC and LCP. A detailed study with PBT shows that char yield does not increase anymore from an optimal ratio of $25 \mathrm{wt} . \%$ of $\mathrm{MDH}$. Therefore, this proves that char promotion appears as one of the main modes-of-action at low MDH content, whereas other mechanisms of fire retardancy become more influent at high MDH content.

Magnesium oxide also allows charring while it avoids early degradation of PBT by hydrolysis. Nevertheless, the char content is significantly lower. It means that the char promotion effect could not be entirely decoupled to the hydrolysis. In other words, the release of water from MDH decomposition promotes not only hydrolysis but also charring through a mechanism that should be further investigated. Water also changes the pyrolysis products from PBT degradation to a certain extent. However, the structure of the residue appears to be the same for MDH and MgO.

Finally, it could be assumed that $\mathrm{MDH}$ or $\mathrm{MgO}$ are good flame retardants for aromatic polyesters as char promoter at low content, and synergy with other flame retardants should be investigated to achieve high rating levels in fire tests. Preliminary tests in cone calorimeter confirm that MDH reduces significantly the flammability of PBT even at low MDH content due to the charring promotion and the associated barrier effect.

\section{REFERENCES}

1. Camino G, Costa L, Luda di Cortemiglia MP. Overview of fire retardant mechanisms. Polymer Degradation and Stability 1991; 33(2):131-154.

2. Laoutid F, Bonnaud L, Alexandre M, Lopez-Cuesta J-M, Dubois P. New prospects in flame retardant polymer materials: from fundamentals to nanocomposites. Materials Science and Engineering: R: Reports 2009; 63(3):100-125.

3. Levchik SV, Weil ED. Flame retardancy of thermoplastic polyesters - a review of the recent literature. Polymer International 2005; 54(1):11-35.

4. Weil ED, Levchik SV. Flame retardants in commercial use or development for polyolefins. Journal of Fire Sciences 2008; 26(1):5-43. 
5. Hull TR, Witkowski A, Hollingbery L. Fire retardant action of mineral fillers. Polymer Degradation and Stability 2011; 96(8):1462-1469.

6. D'Silva K, Fernandes A, Rose M. Brominated organic micropollutants - igniting the flame retardant issue. Critical Reviews in Environmental Science and Technology 2004; 34(2):141-207.

7. De Wit CA. An overview of brominated flame retardants in the environment. Chemosphere 2002; 46(5):583-624.

8. Hollingbery LA, Hull TR. The thermal decomposition of huntite and hydromagnesite - a review. Thermochimica Acta 2010; 509(1-2):1-11.

9. Rothon RN, Hornsby PR. Flame retardant effects of magnesium hydroxide. Polymer Degradation and Stability 1996; 54(2-3):383-385.

10. Hornsby PR, Wang J, Rothon R, Jackson G, Wilkinson G, Cossick K. Thermal decomposition behaviour of polyamide fire-retardant compositions containing magnesium hydroxide filler. Polymer Degradation and Stability 1996; 51(3):235-249.

11. Fei G, Liu Y, Wang Q. Synergistic effects of novolac-based char former with magnesium hydroxide in flame retardant polyamide-6. Polymer Degradation and Stability 2008; 93(7):1351-1356.

12. Durin-France A, Ferry L, Lopez Cuesta J-M, Crespy A. Magnesium hydroxide/zinc borate/talc compositions as flame-retardants in EVA copolymer. Polymer International 2000; 49(10):1101-1105.

13. Hornsby PR, Watson CL. A study of the mechanism of flame retardance and smoke suppression in polymers filled with magnesium hydroxide. Polymer Degradation and Stability 1990; 30(1):73-87.

14. Carothers WH. Studies on polymerization and ring formation. I. An introduction to the general theory of condensation polymers. Journal of the American Chemical Society 1929; 51(8):2548-2559.

15. Pet W. Handbook of Thermoplastic Polyesters. Wiley-VCH Verlag GmbH \& Co. KGaA: Weinheim, FRG, 2002.

16. Bellenger V, Ganem M, Mortaigne B, Verdu J. Lifetime prediction in the hydrolytic ageing of polyesters. Polymer Degradation and Stability 1995; 49(1):91-97.

17. Golovoy A, Cheung MF, Van Oene H. Hydrolysis of polycarbonate/polybutylene terephthalate blend. Polymer Engineering and Science 1988; 28(4):200-206.

18. Kelleher PG, Wentz RP, Falcone DR. Hydrolysis of poly(butylene terephthalate). Polymer Engineering and Science 1982; 22(4):260-264.

19. Gallo E, Braun U, Schartel B, Russo P, Acierno D. Halogen-free flame retarded poly(butylene terephthalate) (PBT) using metal oxides/PBT nanocomposites in combination with aluminium phosphinate. Polymer Degradation and Stability 2009; 94(8):1245-1253.

20. Laoutid F, Ferry L, Lopez-Cuesta J, Crespy A. Red phosphorus/aluminium oxide compositions as flame retardants in recycled poly(ethylene terephthalate). Polymer Degradation and Stability 2003; 82(2):357-363.

21. Laachachi A, Cochez M, Leroy E, Gaudon P, Ferriol M, Lopez Cuesta JM. Effect of A12O3 and TiO2 nanoparticles and APP on thermal stability and flame retardance of PMMA. Polymers for Advanced Technologies 2006; 17(4): 327-334.

22. Lewin M, Endo M. Catalysis of intumescent flame retardancy of polypropylene by metallic compounds. Polymers for Advanced Technologies 2003; 14(1):3-11.

23. Lyon RE, Walters RN. Pyrolysis combustion flow calorimetry. Journal of Analytical and Applied Pyrolysis 2004; 71(1):27-46.

24. Huggett C. Estimation of rate of heat release by means of oxygen consumption measurements. Fire and Materials 1980; 4(2):61-65.

25. Schartel B, Weiß A. Temperature inside burning polymer specimens: pyrolysis zone and shielding. Fire and Materials 2009; 34(5):217-235.

26. Aoyagi Y, Yamashita K, Doi Y. Thermal degradation of poly[(R)-3-hydroxybutyrate], poly[E-caprolactone], and poly[(S)-lactide]. Polymer Degradation and Stability 2002; 76(1):53-59.

27. Kopinke F-D, Mackenzie K. Mechanistic aspects of the thermal degradation of poly(lactic acid) and $\operatorname{poly}(\beta-$ hydroxybutyric acid). Journal of Analytical and Applied Pyrolysis 1997; (40-41):43-53.

28. Kopinke F-D, Remmler M, Mackenzie K, Möder M, Wachsen O. Thermal decomposition of biodegradable polyesters - II. Poly(lactic acid). Polymer Degradation and Stability 1996; 53(3):329-342.

29. Omura M, Tsukegi T, Shirai Y, H Nishida, Endo T. Thermal degradation behavior of poly(lactic acid) in a blend with polyethylene. Industrial and Engineering Chemistry Research 2006; 45(9):2949-2953.

30. Cox FJ, Feudale RN, Johnston MV, McEwen CN, Hauptman E. Pyrolysis-photoionization mass spectrometry of ethylene-methyl acrylate copolymers. Journal of Analytical and Applied Pyrolysis 2002; 64(2):305-312.

31. Sato H, Kikuchi T, Koide N, Furuya K. Thermal degradation and combustion process of liquid crystalline polyesters studied by directly coupled thermal analysis-mass spectrometry. Journal of Analytical and Applied Pyrolysis 1996; 37(2):173-183.

32. Brehme S, Köppl T, Schartel B, Fischer O, Altstädt V, Pospiech D, Döring M. Phosphorus polyester - an alternative to low-molecular-weight flame retardants in poly(butylene terephthalate)? Macromolecular Chemistry and Physics 2012; 213(22):2386-2397.

33. Levchik SV, Weil ED. A review on thermal decomposition and combustion of thermoplastic polyesters. Polymers for Advanced Technologies 2004; 15(12):691-700.

34. Ohtani H, Kimura T, Tsuge S. Analysis of thermal degradation of terephthalate polyesters by high-resolution pyrolysis-gas chromatography. Analytical Sciences 1986; 2(2):179-182.

35. Vijayakumar CT, Fink JK. Pyrolysis studies of aromatic polyesters. Thermochimica Acta 1982; 59(1):51-61. 
36. Buxbaum LH. The degradation of poly(ethylene terephthalate). Angewandte Chemie International Edition English 1968; 7(3):182-190.

37. Lum RM. Thermal decomposition of poly(butylene terephthalate). Journal of Polymer Science, Polymer Chemistry Edition 1979; 17(1):203-213.

38. Sugimura Y, Tsuge S. Studies on thermal degradation of aromatic polyesters by pyrolysis-gas chromatography. Journal of Chromatographic Science 1979; 17(5):269-72.

39. Lyon RE, Walters RN, Stoliarov SI. Screening flame retardants for plastics using microscale combustion calorimetry. Polymer Engineering and Science 2007; 47(10):1501-1510.

40. Sonnier R, Ferry L, Longuet C, Laoutid F, Friederich B, Laachachi A, Lopez-Cuesta J-M. Combining cone calorimeter and PCFC to determine the mode of action of flame-retardant additives. Polymers for Advanced Technologies 2011; 22(7):1091-1099. 